\title{
Equalization for Underwater Acoustic Coded OFDM Communication System Over Multipath Fading Via Simulation Platform
}

\author{
Padmasree challa, M. Satya Anuradha, V.Shireesha, P.Chaya Devi
}

\begin{abstract}
In underwater shallow acoustic communication (UWSAC) channel, due to the reflections from bottom and surface, multiple paths propagated resulting Inter Symbol Interference (ISI). In this paper we present the bit error performance of convolution coded orthogonal frequency division multiplexing (CCOFDM) UWSAC system with the implementation of adaptive equalization to minimize the ISI over $A W G N$ and Rayleigh fading based on Recursive least square (RLS) and Filtered Error Least Mean Squares (FELMS) Algorithms. From the simulation results it is observed that FELMS shown to improve BER as compared to an RLS with CCOFDM system..
\end{abstract}

Keywords:UWSAC,CCOFDM,Channel

Equalization, FELMS, RLS

\section{INTRODUCTION}

UWAC has beenemployed in military affairs, ocean exploration, pollution monitoring[1],etc. In view of these applications, UWAC Technology shows great potential as an area of research. The UWSAC channel has severe ISI due to channel dispersion,thathinders the efficiency of communication devices [2-4].CCOFDM a robust method of encoding digital data on multiple carrier frequencies is used for modulationand has the ability to render ISI negligible by embedding a cyclic prefix. To increase the communication reliability, the receiver will often employ theadaptive equalizer in order to reduce the channel distortion. Specific algorithms are needed to update the filter coefficients and track the channel variations[5]. In this paper RLS and FELMS algorithms are exist.The paper is organized as follows.

In section 2, we discuss the system model and introduce the adaptive filtering algorithms RLS and FELMS for the channel tap coefficients, Section3describes performance of equalization methods over multipath fading that are based on simulation

platform. Finally Section 4 is the conclusion of the paper.

\section{CHANNEL EQUALIATION IN CONVOLUTION CODED OFDM SYSTEM}

The performance of CCOFDM system explanation can be seen in [6]. Let us considered the coded OFDM, at transmitter convolution encoding and data interleaving are used as encoding methods and at receiver the data will be decoded by signal de mapper using de-interleaver and Viterbi algorithm. The transmitted data $s[l]$ is to be on the $l_{\text {th }}$ subcarrier passed through UWSAC channels. The transmitted signal in the pass band is then given by $u(t)=\operatorname{Re}\left\{\left[\sum_{l \in n} s[l] e^{j 2 \pi l \Delta f t} o(t)\right] e^{j 2 \pi f_{c} t}\right\}, t \in\left[0, T+T_{g}\right]$

Where $o(t)$ describes the pulse shaping function. The channel impulse response of channel can be expressed as

$i(\tau, t)=\sum_{a} P_{a}(t) \delta\left(\tau-\tau_{a}(t)\right)(2)$

Where $P_{a}$ is the amplitude of the path and $\tau_{a}(t)$ is the time- varying path delay. Hence the receiver signal in the pass band is then

$$
\hat{c}(t)=u(t) * i(\tau, t)+\hat{v}(t)(3)
$$

Revised Manuscript Received on December 13, 2019.

* Correspondence Author

Padma sreeChalla,Department of ECE , ANITS, Visakhapatnam, India.Padmasreechalla8@gmail.com

M. Satya Anuradha, Department of ECE Andhra University, India. Email: radhamsa@gmail.com

V.Shireesha, ANITS Department of Electronics and Communication engineering VSKP

P.Chaya Devi, Assistant professor at ANITS. Area of research is

Antennas and Communication. 


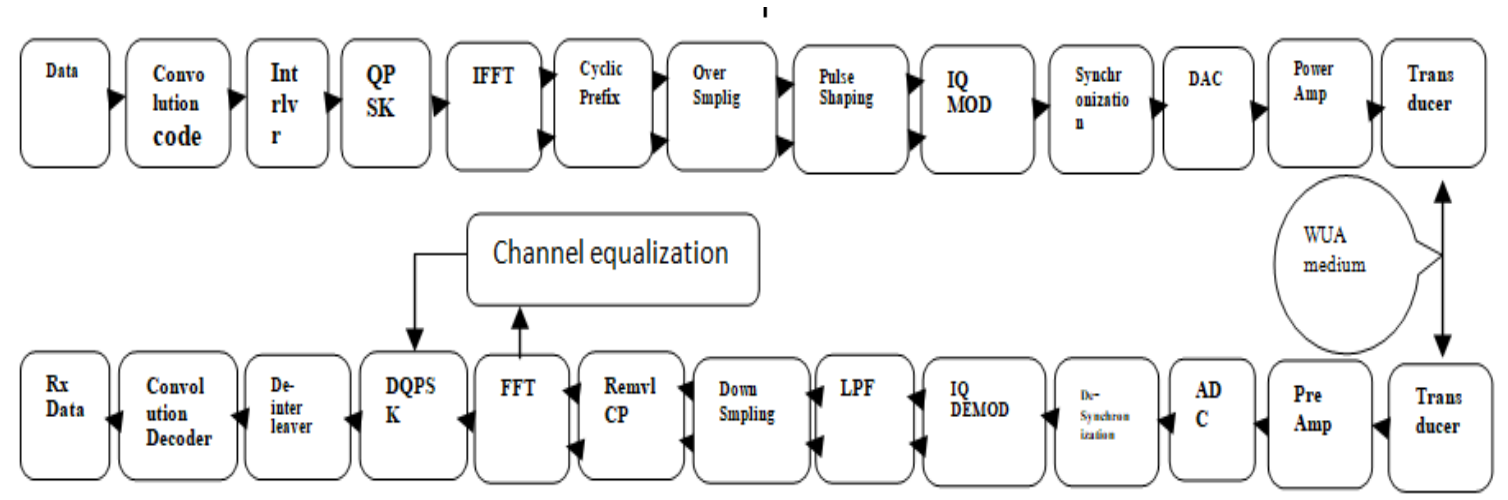

Fig1.Block diagram of CCODED OFDM transceiver system

$\hat{c}(t)=\operatorname{Re}\left\{\sum_{p} P_{a}\left[\sum_{k \in S} s[l] e^{j 2 \pi \| \Delta f\left(t+p t-\tau_{a}\right)} o\left(t+p t-\tau_{a}\right)\right] e^{j 2 \pi f_{c}\left(t+p t-\tau_{a}\right)}\right\}$

$+v(t), t \in\left[0, T+T_{g}\right]$

(4)

Where $v(t)$ is the additive noise. The collected data will be processed by inversion process of the same at source except channel equalizer which uses to estimate the signal. In this paper equalization is based on the RLS and FELMS algorithms. Initially error can be calculated from the received data using

$e(n)=\hat{c}(t)-m(t)(5)$

And then filter coefficients are updated by gain vector $\beta$ it is multiplied by $e(n)$ and input vector $u(t)$ and combine with previous coefficients of the filter. In FELMS without prior knowledge of filter data $\mathrm{F}$ it updates the coefficients is given by

$$
r_{i}=r_{i-1}+\beta(i) u_{i}^{*} F[e(i)], e(i)=d(i)-u_{i} r_{i-1}, i \geq 0
$$

\section{SIMULATION RESULTS}

Simulation result presents the CCODED OFDM with equalization for UWSAC. The BER is evaluated with and without equalization is as shown in fig. 2 and fig. 3 In this simuation image can be considered as input shown in fig. 4 total 49184 number of bits were transmitted at the source. Fig.5 and Fig.6 shows the Received image at SNR $8 \mathrm{~dB}$ and at SNR $17 \mathrm{~dB}$ of RLS equalizer respectively. Fig 7 and 8 shows the Received image at SNR6 dB and at SNR 10dB of FELMS equalizer respectively.

Fig 2. BER Performance of CCODED OFDM over multipath without equalization

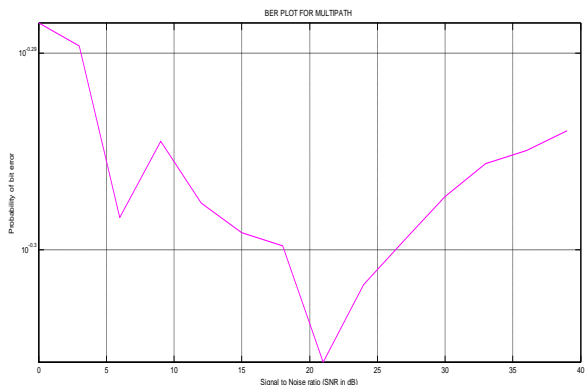

Fig 2. BER Performance of CCODED OFDM over multipath without equalization

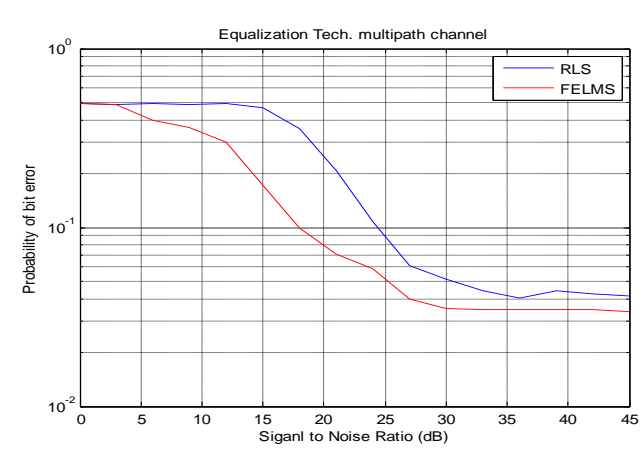

Fig 3. BER Performance of CCODED OFDM over multipath with different channel equalizers.

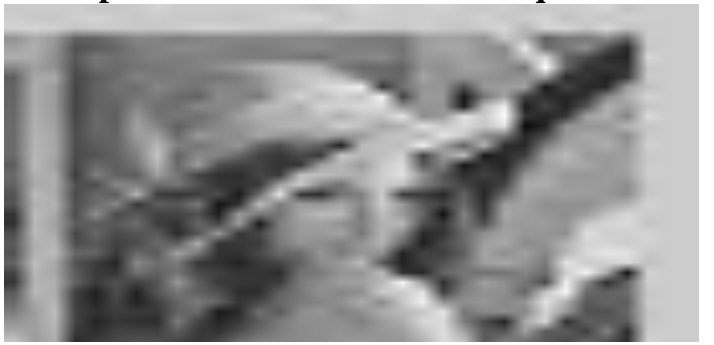

Fig 4. Original image

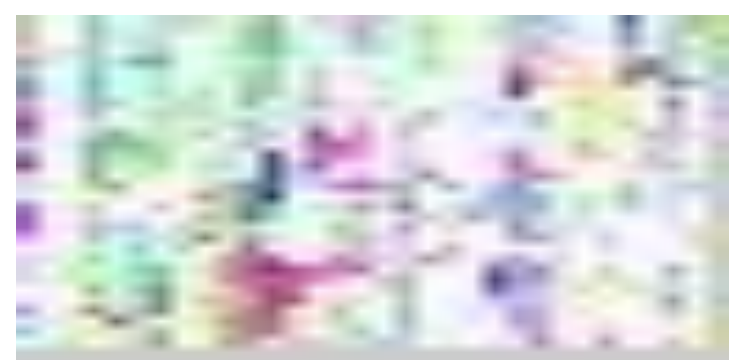

Fig 5. Received image at SNR $8 \mathrm{~dB}$ of RLS equalizer

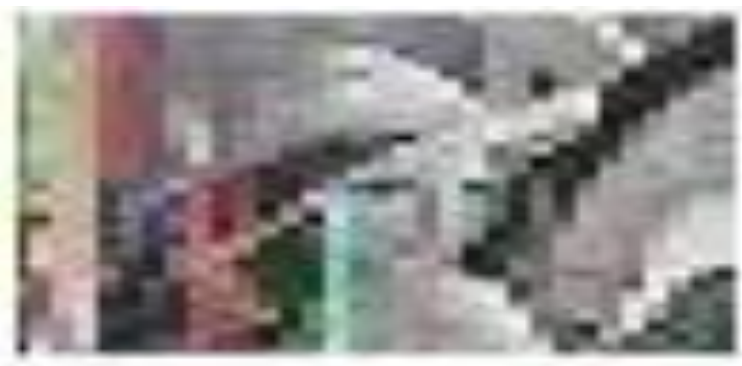

Fig 6.Received image at SNR 17dB of RLS equalizer 


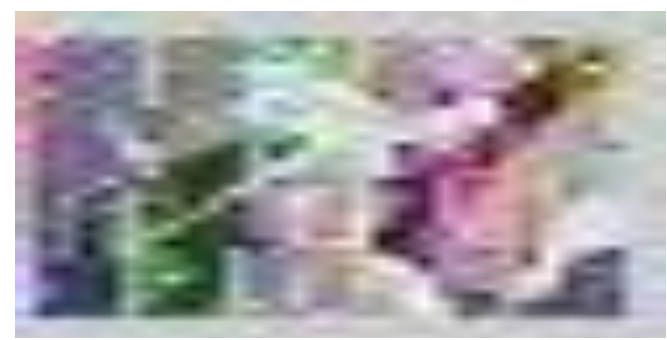

Fig 7. Received image at SNR 6dB of FELMS equalizer

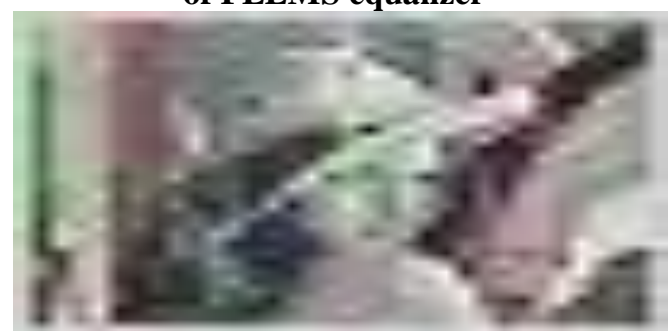

Fig 8. Received image at SNR 10dB of FELMS equalizer

Table 1 represents the SNR VS BER in simulation and Table 2 shows parameters and design values of CCODED OFDM. The signal is recovered at SNR of $18 \mathrm{~dB}$, number of bit errors occurred for RLS is 10831 and for FELMS is 5839.

Table 1. SNR and BER in simulation of CODEDOFDM

\begin{tabular}{|l|l|l|l|}
\hline \multicolumn{4}{|c|}{ Total number of bits transmitted are } \\
\hline SL.NO & $\begin{array}{c}\text { SNR in } \\
\text { dB }\end{array}$ & RLS & FELMS \\
\hline 1 & $\mathbf{0}$ & 49184 & 39810 \\
\hline 2 & 3 & 48741 & 35954 \\
\hline 3 & 6 & 49123 & 29875 \\
\hline 4 & 9 & 46978 & 17303 \\
\hline 5 & 12 & 35772 & 9892 \\
\hline 6 & 15 & 20817 & 7052 \\
\hline 7 & 18 & 10831 & 5839 \\
\hline 8 & 21 & 6155 & 3986 \\
\hline 9 & 24 & 5113 & 3502 \\
\hline 10 & 27 & 4415 & 3454 \\
\hline 11 & 30 & 4010 & 3475 \\
\hline 12 & 33 & 4440 & 3487 \\
\hline 13 & 36 & 4256 & 3485 \\
\hline 14 & 39 & 4147 & 3393 \\
\hline & & & \\
\hline
\end{tabular}

Table 2. parameters and design values of CODED OFDM

\begin{tabular}{|l|l|}
\hline Parameters & Values \\
\hline Modulation scheme & Qpsk \\
\hline Modulating frequency & $6.3 \mathrm{KHz}$ \\
\hline Frequency response & $12-19 \mathrm{KHz}$ \\
\hline Length of IFFT & 256 \\
\hline Equalization methods & RLS ,FELMS \\
\hline
\end{tabular}

\section{CONCLUSION}

From the simulation results we observed that at SNR of $12 \mathrm{~dB}, 35772$ and 9892 bit errors occurred for RLS and
FELMS equalizers respectively. The simulation gives us that the FELMS equalizer has better SNR improvement than RLS Equalization.

\section{REFERENCES}

1. Headrick, R.;Freitag , L.Growth of underwater communication technology in the U.S.Navy. IEEE Commun.Mag.2009,47,80-82. Doi:10.1109/mcom.2009.4752681.

2. Stojanovic, M., "Retrofocusing techniques for high rate acoustic communications", JASA, vol. 117, pp. 1173, 2005.

3. Gomes, J. and Barroso, V., "Time-reversed OFDM communication in underwater channels" IEEE 5th SPAWC Workshop 2004, pp. $626-630$

4. Huang, Jing Sun, et al., "High-speed underwater acoustic communication based on OFDM", IEEE Intnl Symposium on MW Antenna, Propgn and EMC Tech. for Wireless Comms., 2005, vol. 2, pp. 1135-38.

5. digital communications fundamentaland applications BERNARDsklar. Second edition.

6. Padmasreechalla, satyaanuradhamosa performance evaluation and implementation of coded ofdm in wireless underwater acoustic communication.wiley online library.com 2018 DOI:10.1002/dac.3737

\section{AUTHORS PROFILE}

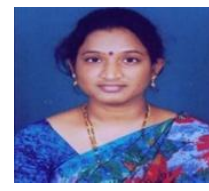

Padmasree Challa Working as Assistant professor at ANITS . Area of research is UNDER WATER ACOUSTIC COMMUNICATION

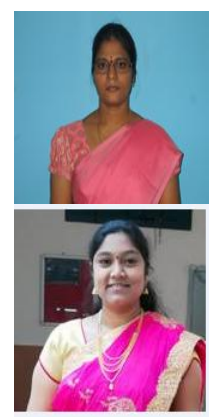

M. Satya Anuradha Working as Professor at Andhra University . Area of research is Antennas, EMI/EMC.

V.Shireesha Working as Assistant professor at ANITS . Area of research is UNDER WATER ACOUSTIC COMMUNICATION

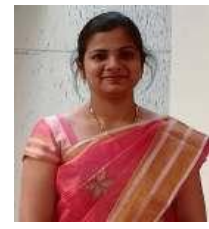

P.Chaya Devi working as Assistant professor at ANITS. Area of research is Antennas and Communication. 